\title{
Open Hardware and Software Robotics Competition for Additional Engagement in ECE Students - The Robot@Factory Lite Case Study
}

\author{
Vítor H. Pinto ${ }^{1,3(凶)}$, Armando Sousa ${ }^{1,3}$, José Lima² ${ }^{\text {, José Gonçalves }}{ }^{2}$, \\ and Paulo Costa ${ }^{1,3}$ \\ ${ }^{1}$ Faculty of Engineering, FEUP - University of Porto, Porto, Portugal \\ $\{$ vitorpinto, asousa, paco\}@fe.up.pt \\ 2 IPB - Polytechnic Institute of Bragança, Bragança, Portugal \\ $\{j 11$ ima, goncalves\}@ipb.pt \\ 3 CRIIS - Centre for Robotics in Industry and Intelligent Systems, INESC TEC - Institute for \\ Systems and Computer Engineering, Technology and Science, Porto, Portugal
}

\begin{abstract}
Throughout this paper, a competition created to enable an interconnection between the academic and industrial paradigms is presented, using Open Hardware and Software. This competition is called Robot at Factory Lite and serves as a case study as an additional enrollment for students to apply knowledge in the fields of programming, perception, motion planning, task planning, autonomous robotic, among others.
\end{abstract}

Keywords: Education - Robotic competitions $\cdot$ Mobile robotics $\cdot$ Portuguese Robotics Open·Robot@Factory

\section{Introduction}

Robotics has more and more impact on daily tasks and that their development allows an increase in the performance of tasks that, until now, were costly and practically impossible for humans. Furthermore, industry is more and more engaged on improving flexibility and adaptability, being an example the Industry 4.0 movement, enabling a global management of material and human resources, optimizing these two aspects.

Professors in several Engineering fields, which typically are researchers in that area, begin to realize the advantages that robotics can bring to their specific field of interest. Specifically, teachers from Electrical and Computers Engineering (ECE) should promote students' interest in areas they like and where they are most likely to find a job. Project Based Learning (PBL) is proven to be a very effective method in several areas, like Science, Technology, Engineering and Mathematics (STEM) [1], Medicine [2], Biology [3], Economics [4], being these just examples of the multiplicity of areas in which PBL is effective.

Typically, students in the ECE field of study are attracted for practical activities but also for activities framed in areas that can provide useful learning for career opportunities and curriculum. Throughout this paper, a competition created to enable an interconnection between the academic and industrial paradigms is presented, using Open Hardware

(C) The Editor(s) (if applicable) and The Author(s), under exclusive license

to Springer Nature Switzerland AG 2021

J. A. Gonçalves et al. (Eds.): CONTROLO 2020, LNEE 695, pp. 729-739, 2021.

https://doi.org/10.1007/978-3-030-58653-9_70 
and Software. This competition is called Robot at Factory Lite and serves as a case study as an additional enrollment for students to apply knowledge in the fields of programming, perception, motion planning, task planning, autonomous robotic, among others.

This paper is organized with the Introduction in Sect. 1, followed by the Related Work in Sect. 2. In Sections 3 and 4 the open-source Hardware and Software modules of the robotic platform are presented, respectively. Section 5 presents the obtained results and in Sect. 6 the conclusions withdrawn from this work, as well as possible future work.

\section{Related Work}

Robotic competitions are a proven way to find "out of the box" solutions for difficult problems, that otherwise would be extremely hard. These events bring together a teams of people focused on the same objective, interested in a common set of thematic and working to build a solution to solve a problem. This competitive mindset thrills the participants and encourage them to overcome complex problems in different areas of competition [5]. Thanks to the participants' spirit, this kind of competitions lead to innovative solutions for societal problems and great technological advances [6]. There are numerous robotic competitions in all robotics fields, such as SAUC [7] for Marine Robotic Vehicles, the DARPA Robotics Challenge for Ground Robots [8] and even Multi-Type Competitions, as euRathlon, that combines all the mentioned types of vehicles to achieve a certain goal [9]. Using robotic competitions to improve the field's technology is a very powerful tool that allows a more motivated learning, with a marked interpersonal component that allows at the same time a sharing of knowledge that may even surpass that of a conference. Portuguese Robotics National Competition have a competition called Robot@Factory [10] providing challenges that can be found in real industrial factories, using Autonomous Guided Vehicles (AGVs) to transport boxes from an entrance warehouse to the exit one, passing through some production machinery. Robot@Factory Lite (R@F Lite) competition was inspired in this major league competition, adding new components, such as RFID identification of the boxes, the introduction of an electromagnet to transport the boxes, among other changes [11], and served as a case study. As the authors of [12] clearly support, educational robots can be used as programming project, learning focus and collaborator. Robotic Competitions for teaching graduate students are a way to increase knowledge in the areas of programming languages, mechanical construction, sensors and their respective data acquisition, actuators and the respective drivers, etc. To do this, it is necessary to create a way for students to use this knowledge, creating platforms that allow this development. There are several open hardware and software platforms used to teach students in broad areas, such as [13], [14] or [15]. These are good examples of how open-source platforms are a great asset for STEM education.

\section{Open Hardware Description}

In order to motivate students to the proposed challenge, a hardware and software prototypes of a robot are provided at: https://github.com/P33a/SimTwo/tree/ master/RobotFactoryLite. The hardware module is composed by several components, 
as described. Table 1, with a Bill of Materials, is presented in the end of this section, containing links to a sample provider's page, as well as indicative prices.

- Arduino based microcontroller: Arduino UNO or arduino nano with a easy connections shield is suggested to facilitate connections between peripherals and the microcontroller and also to use the arduino IDE, a well-known programming environment.

- RFID: A SPI protocol radio-frequency identification reader to identify the part type.

- Part switch detector: a switch to be assembled on the front of the robot to detect the presence of the part.

- Batteries: two 18650 lithium batteries to supply the robot

- Step Down converter: A switching converter to supply the $5 \mathrm{~V}$ components in an efficient way.

- Motor driver: Receives the signals (PWM and direction) from the microcontroller and actuates the motors.

- Electro-Magnet: A magnet controller by a bit is used to hold the part while moving on the floor.

- Motors: Two Geared motors (left and right) are used to move the robot in a differential architecture.

- Floor line detector: A PCB composed by 5 infra-red emitters and receivers is used to detect the white line on the floor. It is used to follow the line during the competition.

- Reverse voltage protection circuit: based on a $\mathrm{N}$ channel mosfet with a low resistance $R_{D S}^{o n}$ protects the electronic components against wrong batteries connections (see Fig. 1 for the circuitry).

- Power button: an electronic switch (Fig. 2) is used to control the supply of the robot. The main function is to power off the robot when the batteries voltage is below a threshold to protect them against low state of charge.

- stl files: All 3D parts that compose the robot are available in stl format and ready to be printed in a $3 \mathrm{D}$ printer.

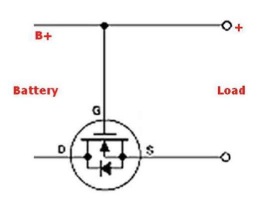

Fig. 1. Reverse voltage protection circuit.

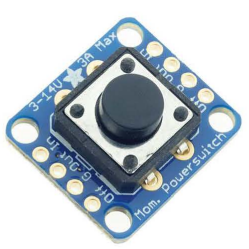

Fig. 2. Power switch.

It is also provided a schematic that helps students and supervisors to build, in a easy way, the mobile robot. The schematic is presented in Fig. 3.

The complete assembly of the robot can be seen in Fig. 4.

Due to the restricted number of I/O pins the end switch sensor shares the same pin as the MOSI line the is connected to the RFID reader. The end switch can pull the 


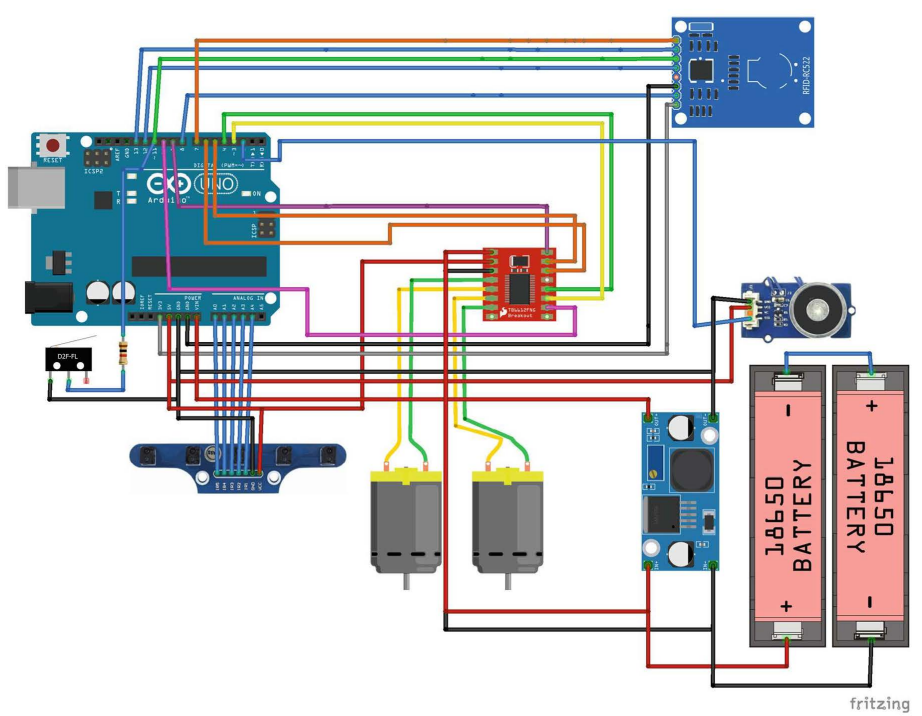

Fig. 3. Robot schematic.

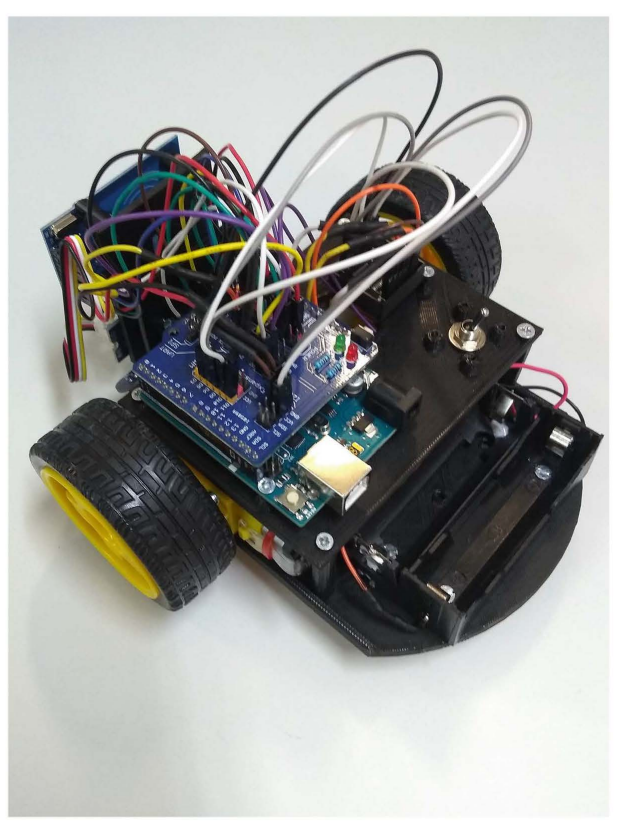

Fig. 4. Assembled robot 
MOSI pin to the ground through a $1 \mathrm{k} \Omega$ resistor. That way, when the MOSI pin is being used to communicate with the RFID reader it acts as an output and the state of the end switch can't affect the signal level. When the communication is paused, the MOSI pin can be toggled to act as an input with the internal pull-up on. That way, if the end switch connects the $1 \mathrm{k} \Omega$ resistor to the ground the input level will be near $0 \mathrm{~V}$ and the micro-controller will read the input as a zero.

byte readTouchswicth (void)

\{

byte ret;

pinMode (TOUCHSW, INPUT_PULLUP); // Change to input with pullup ret $=$ !digitalRead (TOUCHSW) $; / /$ Read zero means pressed pinMode (TOUCHSW, OUTPUT); // Change back to output

return ret;

\}

Table 1. Bill of materials

\begin{tabular}{|c|c|c|c|c|}
\hline \multicolumn{5}{|l|}{ Robot@Factory Lite } \\
\hline Component & Link & Unit price & Quantity & Total \\
\hline Motor + wheel (2x) & $\begin{array}{l}\text { https:/www.botnroll.com/en/dc-motor/2975-hobby- } \\
\text { gearmotor-200rpm-65mm-wheel.html }\end{array}$ & $€ 2.90$ & 2 & $€ 5.80$ \\
\hline RFID reader & $\begin{array}{l}\text { https:/www.botnroll.com/en/rf-lora/2580-rfid-module- } \\
\text { rc522-kit-13-56mhz-6cm-with-tags-s50.html }\end{array}$ & $\Theta 4.90$ & 1 & $€ 4.90$ \\
\hline Line sensor & $\begin{array}{l}\text { https://www.botnrollcom/en/infrared/2586-tracker- } \\
\text { sensor-infrared-line-tracking.html }\end{array}$ & $€ 6.50$ & 1 & $€ 6.50$ \\
\hline Magnet & $\begin{array}{l}\text { https:/www.botnroll.com/en/solenoides/976-grove- } \\
\text { electromagnet.html }\end{array}$ & $€ 12.60$ & 1 & $€ 12.60$ \\
\hline Castor & $\begin{array}{l}\text { https://www.botmroll.com/en/wheel/604-rodizio- } \\
\text { miniatura.html }\end{array}$ & $€ 2.90$ & 1 & $€ 2.90$ \\
\hline Battery support (2x) & $\begin{array}{l}\text { https } / / \text { www.botnroll.com/en/accessories/1299-support- } \\
\text { for-1-battery-mr18650-w-wires.html }\end{array}$ & $€ 1.00$ & 2 & $€ 2.00$ \\
\hline Motors driver & $\begin{array}{l}\text { https://www.botnroll.com/en/controllers/1957-adafruit- } \\
\text { tb6612-12a-dcstepper-motor-driver-breakout-board-. } \\
\text { html }\end{array}$ & $€ 5.90$ & 1 & $€ 5.90$ \\
\hline Arduino nano & $\begin{array}{l}\text { https://www.botnroll.com/en/arduino-boands/934- } \\
\text { arduino-nano-30-compativel.html }\end{array}$ & $€ 12.90$ & 1 & $€ 12.90$ \\
\hline Arduino nano shield & $\begin{array}{l}\text { https:/www.botnroll.com/en/shield-prototype/2373- } \\
\text { nano-io-shield-for-arduino-nano.html }\end{array}$ & $€ 9.60$ & 1 & $€ 9.60$ \\
\hline Lithium battery (2x) & $\begin{array}{l}\text { https:/www.botnroll.com/en/batteries/2300-re-battery- } \\
\text { li-ion-mr18650-37v-2550mah.html }\end{array}$ & $\Theta 4.90$ & 2 & $€ 9.80$ \\
\hline Step down converter & $\begin{array}{l}\text { https:/www.botnroll.com/en/dcdc-converters/937- } \\
\text { lm2596-step-down.html }\end{array}$ & $€ 3.90$ & 1 & $€ 3.90$ \\
\hline Micro switch & $\begin{array}{l}\text { https:/www.botnroll.com/en/switchs-buttons/2026- } \\
\text { microswitch-with-roller-.html }\end{array}$ & $€ 0.90$ & 1 & $€ 0.90$ \\
\hline & & & Total & $\in 77.70$ \\
\hline
\end{tabular}




\section{Software Architecture}

There are two ways of developing the software solution. The first one is to program the robot directly on the Arduino IDE and test it on the maze. On the other way, it can be used the Hardware-in-the-loop approach, where a simulator (SimTwo provided environment - see Fig. 5) is applied and the Arduino communicates with the simulator thought USB port. This way, solution can be easily validated and adjusted with a simulator with the real limitations of the microcontroller. The same code can be used both for real and simulated robot.

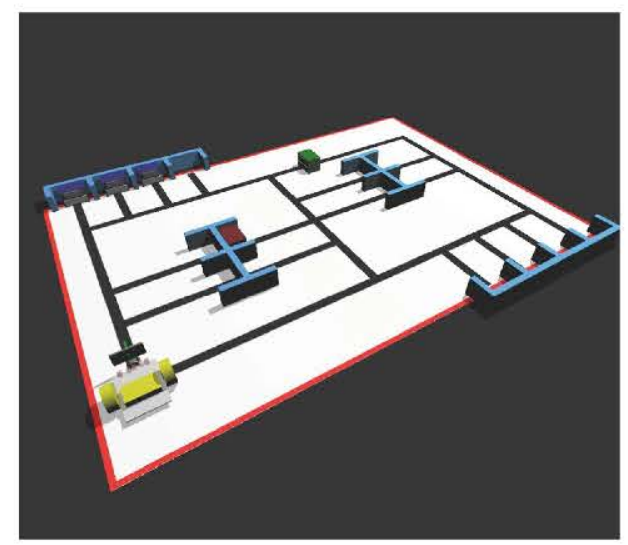

Fig. 5. SimTwo simulator

The robot can be controlled by a high level state machine that decides the current action. Possible current actions, already implemented, are provided by the functions:

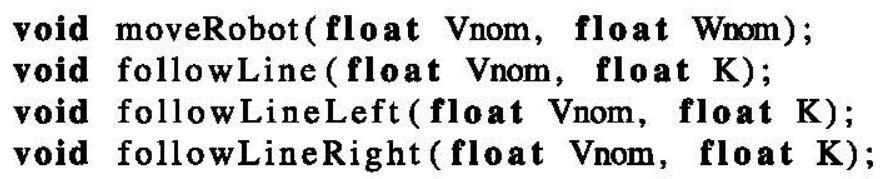

The action moveRobot sets the linear speed $\mathrm{v}$ and the angular speed $\mathrm{w}$. It can be used to blindly, go straight ahead, turn, perform a curve with a certain radius or simply stop (when $v=0$ and $w=0$ ). The units for $v$ and $w$ are not calibrated as the absence $o$ motor encoders makes the speed dependent on the battery voltage level and the friction from the transported payload. In the future, a version with motors fitted with encoders can overcome this problem at a slightly higher cost. The other actions make the robot follow a black line using an reference, respectively the center of the line, the left edge or the right edge. The parameter Vnom sets the desired linear speed and $\mathrm{K}$ is the feedback gain that controls how much correction effort is applied on the angular speed. A simple state machine that makes the robot travel the first part to be moved a bring that part to its destination was made available as an example. It could be used as a starting point and as a way to verify if the hardware was working properly. The state machine is presented in next diagram. 


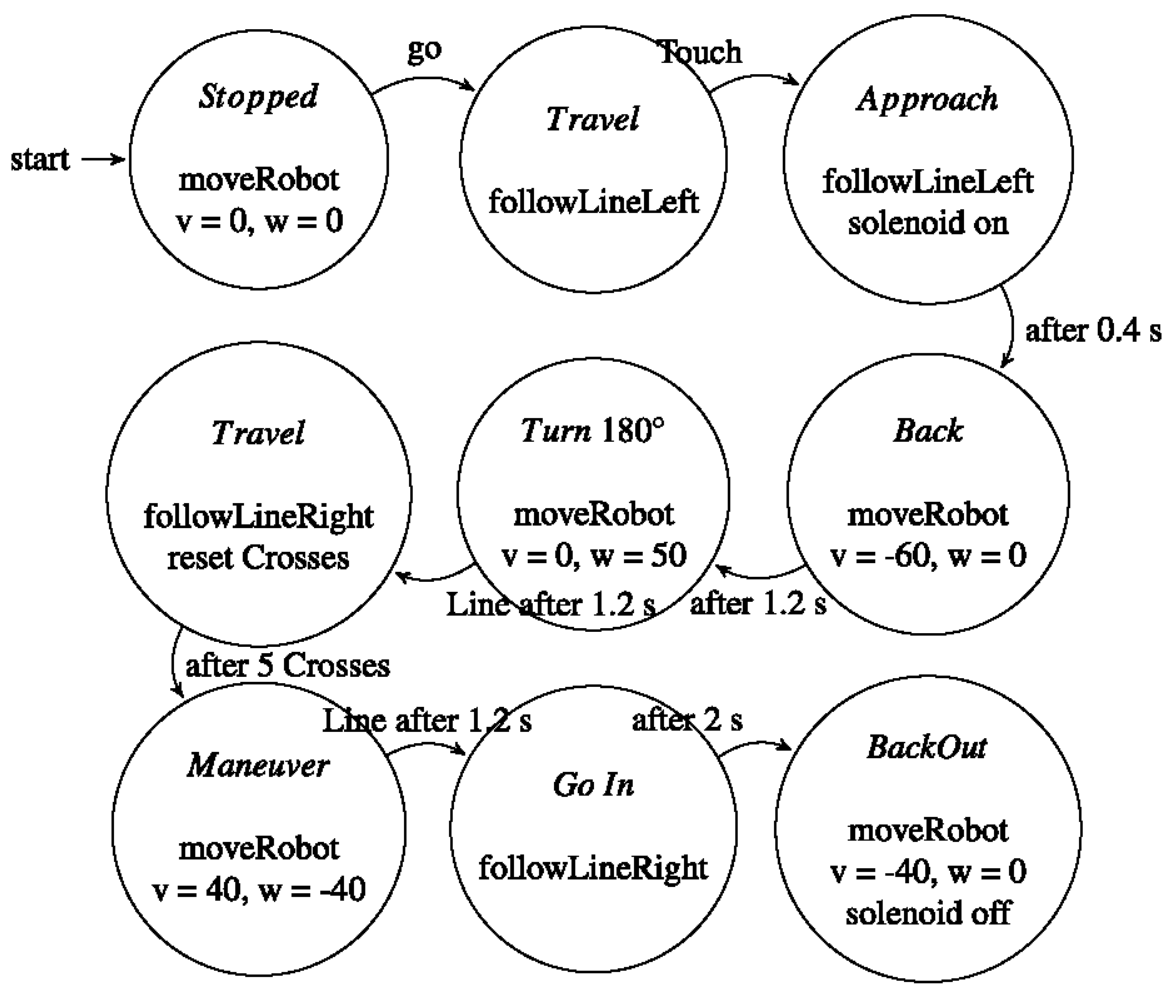

\section{Findings}

As mentioned before, The R@FLite competition targets mainly late secondary education and early higher education (HE) students and is meant to be an entry level competition for busy students in a challenging academic environment. This article will focus on HE students in the 2019 Portuguese Robotics Open (PRO), the first year that this competition occurred. The current section will address findings. The data gathered comes from 3 data sources: (i) official enrollment data from the R@FLite competition; (ii) a survey to participants and (iii) interviews with mentors of the teams and organizers. From official enrollment data it is known that a total of 20 students entered the competition on 5 teams, all teams with 4 students. One team came from the Instituto Politecnino de Bragança (IPB) and 4 from the Faculdade Engenharia da Universidade do Porto (FEUP) both from Portugal.

\subsection{Survey to Participants}

To assess the general and educational interest of this competition the participants were asked to answer a quiz. The quiz includes answerer characterization, time invested in the competition and learning/interest in the competition. The mentioned quiz also has open responses regarding learning, strong points and points to improve. The students targeted in this quiz are 18 year old or older and were contacted by email roughly one 
month after the competition. The email directed to an anonymous quiz implemented with Google Forms. The 20 emails were sent by each team mentor twice, one week apart.

\subsection{Responses and Analysis}

The quiz totaled 15 answers ( 4 from IPB and 11 from FEUP). From IPB, 3 students were enrolled in the 5th final year and one in the 1st initial year of the Electrical and Computer Engineering (ECE). Regarding quiz responders from the FEUP's ECE course, 1 student came from the first year, 4 from the 3rd year and 6 from the 4th year. Globally, less students (6) had this participation articulated with an academic degree that the opposite (6).

Total Personal Work Time (t)

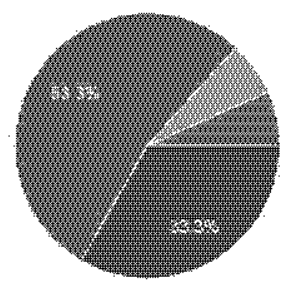

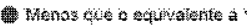

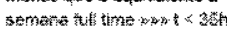

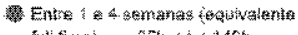
fut: time was

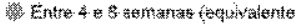

能

Whats do qua 6. Wemanas

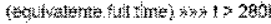

Total Work Time for the Team (t in person $x$ hour)

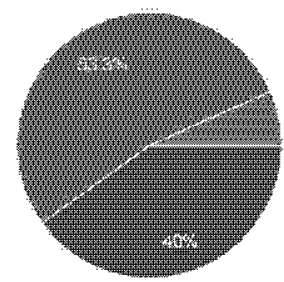

Menos de 4 pessoas $\times 4$ semana $2.22: 4<140 \mathrm{ph}$ (ph $=$ pessega $\times$ horat

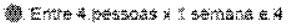

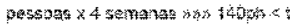
s sou th

然

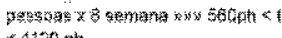
स1120, th.

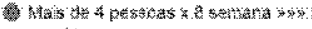

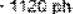

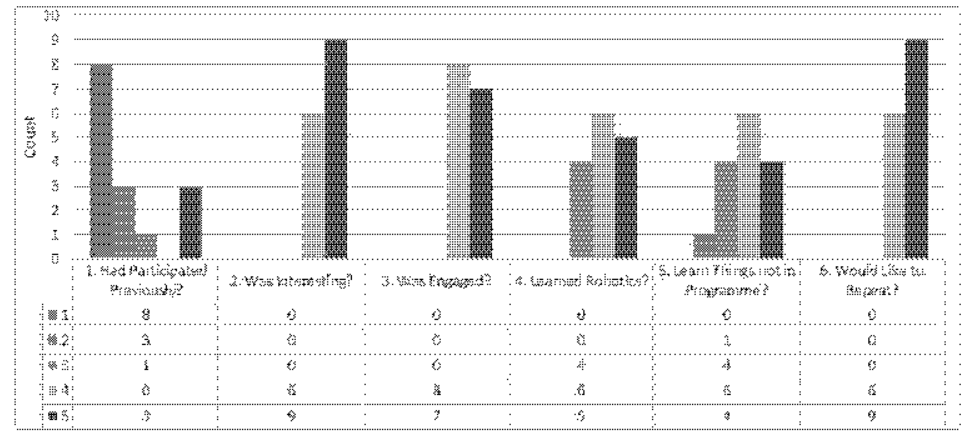

Fig. 6. Histogram of quiz responses 
The answers are summarized in Fig. 6 show that most common working time is form one week to 4 weeks full time equivalent (FTE, weeks of $35 \mathrm{~h}$ of work). This seems articulated with most common answer of total work time for the team ranging from 4 person week to 16 person week. Not surprisingly, a manual detailed analysis reveals that individual students that have academic coordination have spent, in average, more time with the competition. The next section of the quiz asked for Lickert scale agreement to some questions using numeric encoding as $1=$ No or Disagree, 3 $=$ Average or Neutral, $5=$ Yes or Agree. Further inquiries from the same quiz reveal that the vast majority had not participated in previous robotics competitions (average 2.3) and that the participation was interesting (average 4.6) and engaging (4.5). Interestingly, participants seem eager to repeat a future participation, likely due to the competitive mindset. The same quiz (Fig. 6) reveals some dispersion in learning issues, 4 responders declaring that learning with the participation was " 3 Neutral" and average of answers is 4.0. A most interesting question is if the robotics issues that students "learned" had been addressed in the program. Answers reveal some dispersion, likely related to student's academic year - students state "Learned things not in the Program" average score of 3.8 and standard deviation of 0.9 (which is larger than for other questions). In the open text, 2 students identified State Machines as a main topic of interest and another student pointed out the importance of building a robot mostly from elementary components. These two ideas were the only two ideas all mentors mentioned. This hints the importance of open software (inducing healthy programming habits) and open hardware further reinforces deep learning as the robot is all done by the team and the team has mechanic, electronic and programming layouts readily accessible. Mentors also state the importance of open hardware and open software to keep complexity at an interesting level and promote problem solving capabilities.

\section{Conclusions and Future Work}

The shown results hint that the Robot at Factory Lite competition is interesting to students that state high levels of interest and engagement even if not a huge amount of time is dedicated. This is interesting to allow for easy coordination with other academic duties such as classes and intermediate tests that keep their normal pace during competition time.

The students affirm some learning and mentors and organizers find this knowledge to be of practical nature, crossing all of the hardware and software levels. Such knowledge type is not easy to address in ECE regular courses, especially in massified faculties. Admittedly, the same kind of knowledge might be attained by Project Based Learning or in capstone courses dedicated to those outcomes. Most students state that they worked less for this competition than they would have for a 6 ECTS course (162 h). Many of these students did this work extra class for no academic merit (and this further hints attractiveness). Open hardware and software are also a part of this attractiveness as otherwise the challenge would not be solvable in such a low amount of time.

It makes sense that such competitions be articulated into academic curricula in HE in order to achieve practical skills and "learn by doing" and "problem solving" knowledge. Participants recognize that some learning is not addressed in normal curricula. 
Mentors state the importance of open hardware and software to complete full knowledge of a fully functional system robotic made by the students themselves. Many of the involved also state transversal engineering skills, soft skills and global engineering skills to be improved by participation in the mentioned competition.

Further inquiries are necessary to establish statistical relevance but answers hint that the Robot at Factory Lite competition motivates and complements a common ECE curricula. Admittedly, such benefits are likely to be common to other educational practices. Longer and more detailed surveys are necessary to have solid hints as to what is being learned in this competition that is not addressed in the curricula or if it is only a matter of something that has not yet been addressed at the year the student is presently at.

Acknowledgements. This work is financed by National Funds through the Portuguese funding agency, FCT - Fundação para a Ciência e a Tecnologia, within project UIDB/50014/2020.

\section{References}

1. Han, S., Rosli, R., Capraro, M., Capraro, R.: The effect of science, technology, engineering and mathematics (STEM) project based learning (PBL) on students' achievement in four mathematics topics. J. Turk. Sci. Educ. 13(Specialissue), 3-30 (2016). Accessed by 8 . https:// www.scopus.com/inward/record.uri?eid=2-s2.0-84999098096\&doi=10.12973

2. Alrahlah, A.: How effective the problem-based learning (PBL) in dental education. A critical review. Saudi Dent. J. 28(4), 155-161 (2016). http://www.sciencedirect.com/science/article/ pii/S1013905216300396

3. Thakur, P., Dutt, S.: Problem based learning in biology: its effect on achievement motivation of students of 9th standard. Int. J. Multi. Educ. Res. 2(2), 99-104 (2017)

4. Madsen, M.O., Olesen, F.: Teaching economics at Aalborg University using the PBL approach. Department of Business and Management Working Paper Series, No. 5, 2016. Department of Business and Management (2016). http://www2.business.aau.dk/digitalAssets/226/ 226176_wp-pbl-16.pdf

5. Costa, V., Rossetti, R., Sousa, A.: Simulator for teaching robotics, ROS and autonomous driving in a competitive mindset. Int. J. Technol. Hum. Interact. 13(4), 19-32 (2017). https:// doi.org/10.4018/LJTHI.2017100102

6. Dias, J., Althoefer, K., Lima, P.U.: Robot competitions: what did we learn? [competitions]. IEEE Rob. Autom. Mag. 23(1), 16-18 (2016)

7. Ferri, G., Ferreira, F., Djapic, V.: Fostering marine robotics through competitions: from SAUC-E to ERL emergency 2018. In: OCEANS 2018 MTS/IEEE Charleston, pp. 1-7, October 2018

8. Krotkov, E., Hackett, D., Jackel, L., Perschbacher, M., Pippine, J., Strauss, J., Pratt, G., Orlowski, C.: The DARPA robotics challenge finals: results and perspectives, pp. 1-26. Springer, Cham (2018). https://doi.org/10.1007/978-3-319-74666-1_1

9. Sousa, P., Ferreira, A., Moreira, M., Santos, T., Martins, A., Dias, A., Almeida, J., Silva, E.: ISEP/INESC TEC aerial robotics team for search and rescue operations at the euRathlon 2015. J. Intell. Rob. Syst. 93(3-4), 447-460 (2019)

10. Costa, P.J., Moreira, N., Campos, D., Gonçalves, J., Lima, J., Costa, P.L.: Localization and navigation of an omnidirectional mobile robot: the robot@factory case study. IEEE Revista Iberoamericana de Tecnologias del Aprendizaje 11(1), 1-9 (2016)

11. Lima, J., Costa, P., Brito, T., Piardi, L.: Hardware-in-the-loop simulation approach for the robot at factory lite competition proposal. In: 2019 IEEE International Conference on Autonomous Robot Systems and Competitions (ICARSC), pp. 1-6, April 2019 
12. Miller, D.P., Nourbakhsh, I.R., Siegwart, R.: Robots for Education, pp. 1283-1301. Springer, Heidelberg (2008), https://doi.org/10.1007/978-3-540-30301-5_56

13. Mejías, A., Herrera, R., Márquez, M., Calderơn, A., González, I., Andújar, J.: Easy handling of sensors and actuators over TCP/IP networks by open source hardware/software. Sensors 17(1), 94 (2017)

14. Arvin, F., Espinosa, J., Bird, B., West, A., Watson, S., Lennox, B.: Mona: an affordable opensource mobile robot for education and research. J. Intell. Rob. Syst. 94(3), 761-775 (2019). https://doi.org/10.1007/s10846-018-0866-9

15. Pinto, V.H., Monteiro, J.M., Gonçalves, J., Costa, P.: Prototyping and programming a multipurpose educational mobile robot - NaSSIE. In: Lepuschitz, W., Merdan, M., Koppensteiner, G., Balogh, R., Obdržálek, D. (eds.) Robotics in Education, pp. 199-206. Springer, Cham (2019) 